\title{
Understanding Factors Influencing E-Government in Saudi Arabia
}

\author{
Walid Qassim Qwaider, PhD \\ Majmaah University \\ College of Science and Humanities in Ghat \\ Management Information Systems Dept. \\ Saudi Arabia
}

\author{
khaled Abdullah AL Shafi, PhD \\ Majmaah University \\ College of Science and Humanities in Ghat \\ Law Dept. \\ Saudi Arabia
}

\begin{abstract}
The Kingdom of Saudi Arabia rise through the ranks of United Nations report prepared stands at $58^{\text {th }}$ in the world, and $4^{\text {th }}$ in the Gulf region in preparation for e-government, according to United Nations reports. In particular, has been ranked the Kingdom of Saudi Arabia in all over the world for its online service index $75^{\text {th }}$. While this is still modest for the aspirations of the Saudi government to see to the implementation of e-government in 2013.

The aim of this paper is to study the activities of egovernment in the Kingdom of Saudi Arabia, and to identify the factors currently impeding the development and implementation of e-government in this country. While issues such as technological issues, cultural and organizational, and social that should be considered and handled carefully by any government considering adoption in Saudi Arabia, this research indicates that factors such as access to the Internet and the integration of various government agencies also constitute a major challenge of e-government to be implemented in Saudi Arabia, and the implementation of egovernment is the lack of strategic frameworks, leadership, and legal and regulatory issues related to infrastructure
\end{abstract}

\section{Keywords}

E-government, Developing Countries, Saudi Arabia, ICT, Integration Approaches.

\section{INTRODUCTION}

Government's focus on achieving high efficiency in the provision of services to citizens, as well as the exchange of information between departments and institutions in a short time and in an easy way [1].

Many countries to take advantage of the full feature of information technology to enhance relationships and interactions between companies and individuals, governments and governments all over the world from the application of methods and systems for the implementation of electronic processes, and provide significant benefits for citizens, governments and businesses [2]. Surveys of the United Nations E-Government in 2003 in order to assess the 192 member states to take advantage of modern technologies such as information and communication technology and the World Wide Web in the public sector [3]. Polls motive behind the United Nations is to make useful survey reports for governments, researchers, the private sector and civil society representatives in order to get a deeper understanding [4].

The main objective of this research is to evaluate the scenario of e-government in Saudi Arabia, using e-government surveys and indicators of the United Nations and compare it with the performance of Bahrain. Determine the facts of this research some of the weaknesses that are likely to affect the value of the index of indicators of e-government in the United Nations. Finally, suggestions, and measuring the three communications services over the Internet, and sub-indices, and human capital to improve e-government in Saudi Arabia.

\section{RELATED WORK}

There have been a number of studies that focus on egovernment experiences of many developing countries all over the world. Many of these studies examine the effects, and effects, and the challenges and issues of implementation of egovernment from the point of view of developing countries [5].

Alshomrani, in the scenario and to achieve e-government development in the Kingdom of Saudi Arabia and comparison with the United States. The study is based on the reports of egovernment survey conducted by the United Nations between 2003 and 2010 [13]. The experience of the United States government electronic States, and report made some observations important for us concerning the Kingdom of Saudi Arabia e-government. This study also provided us with proposals and counter measures to improve e-government in the Kingdom of Saudi Arabia [3].

Bliss assesses the current state of e-Government Arabia by evaluating Web sites and ministries' using citizen-centered egovernment approach. Interactive e-government services coiled within the limits of existing frameworks screening evaluation in literature while at the same time to build their strengths. Framework of this study evaluates quantitative stages of the ministry's website on the Internet Arabia and problems of e-government. Found that $8(41 \%)$ of the 21 ministries did not implement the main features of egovernment Web site. In addition, the 10 ministries (45.4\%) in whole or in part in the stage (and web presence), 3 Ministries (13.6\%) were in the second stage (in one direction interaction); and 6 ministries not Internet service at all. These results clearly show that the ministries were not assess citizencentered Web sites and e-government transaction services lacking, leading to citizens discontent and frustration [6].

Meso and others. Al. How do you achieve national information and communication and dissemination of technology (ICT) in the politics of Egypt and why there is differential awareness of policies between different sectors or occupations. The results indicate that the critical element for the implementation of IT strategies and national communication involves the correct positioning of the policies of information and communication technology. This is especially true for developing countries, where it is to look at the effects of information and communication technology to take advantage of the economic and social development and [7] crucial. 


\section{THE LEGAL FRAMWORK FOR E- GOVERNMENT IN SAUDI ARABIA}

As is known, appeared with the mid-nineties the beginnings of knowledge management, and the world lived this information revolution, and technical development, hence the states need to be racing against time in the recruitment of technical completion of the work high standards to ensure fast delivery and save time, money and effort [14].The Kingdom of Saudi Arabia from the Arab countries made good steps in the recruitment of technical and shift to e-government through the adoption of communications systems, information technology and activate used to access the information society and digital economy, as well as achieving rates higher than welfare of the citizens and residents and to facilitate things, their living conditions. Kingdom was able to develop government work and spread the concept of electronic transactions in the various government agencies [15].

To that end adopted a Saudi national strategy and five-year plans and promising, ambitious and entrusted to the egovernment program developed and implemented in collaboration with government agencies, has been completed operational plan first e-Government, which was from the year 2006 to the year 2010 was the launch of the operational plan second of the year 2012 to2016. In this context, put the Kingdom of the necessary strategic and operational plans for this ambitious project a shift to e - government, and the role of the legislative branch in the Kingdom an important role in the enactment of laws and regulations that ensure comprehensive legal framework to deal with this project. The legal construction of e-government of the most topics importance and sensitivity, challenges the legal e-business require a change in the mechanisms and means of dealing government with domicile in a lot of services that offer to him and which vary aspects of the administrative and financial, as well as mechanisms to pay taxes and collection of receivables governmental organizations and others, the security information to the parties to the service provider and the beneficiary, providing privacy and confidentiality of all transactions that require this [16].

It is noteworthy that the transition to e-government in the Kingdom was not a quick and surprise even taking the principle of gradual and create the infrastructure and the legal environment was promulgated Council of Ministers Resolution No. (7 / b / 26345 ) dated 12/19/1422 H for government building databases to fulfill for use in facilitating transactions with other government agencies in the preparation of annual reports on the work side and according to the paragraph " 5 " of the decision to the Prime Minister referred to above, and the decision was supportive largely to government bodies being issued by the legislative authority in the country and represents the direction of the kingdom and policy framework towards becoming e-government .Taking the principle of gradual second step was the decision of the Council of Ministers which represents the country's legislative authority No (235) dated 08/20/1425, the transition from traditional to electronic means, according to the text of the third paragraph of the resolution: "Government agencies to expedite the adoption of the use of systems computers in all financial operations and accounting, and a shift from the traditional means in the bookkeeping and the preparation of accounts and financial statements to electronic means and submit their data for review on CD-ROM instead of paper documents, "and it was this decision a significant impact in supporting the implementation of e-government through the adoption of governmental regulations informatics and abandon the conventional methods, which helped to develop methods of management of government facilities, and raise the level of performance and provide accurate information.

Then Council of Ministers Resolution No. ( 8189 / m b) and the date of 19/06/1426 H for government formation of internal committees for electronic transactions linked to the administrator first in the device, and entrusted the Committee everything related to transactions online, and select a number of responsibilities and tasks that elevate and accelerate the transition to e-government . And continued legislator Saudi Arabia and through the legislative authority to issue decisions and frame the areas of e-government was promulgated Council of Ministers Resolution No. ( $8189 / \mathrm{m} \mathrm{b}$ ) and the date of 19/06/1426 AH approval controls the application of egovernment in government agencies and ensure the resolution steps more accurate and the process towards inclusive of egovernment and reduce the traditional character of the government institutions where resolution set of information and government data accurately and census detail, and ensure the resolution business and government services and applications of e-government claimed all government institutions and the government launched through this program, the establishment of national Portal Services egovernment, to facilitate access to government information and access to government services. In the same context, a law was passed against cybercrime by Royal Decree No. (M/ 17 ) dated 03/08/1428 AH which is designed to reduce the emergence of cybercrime by identifying those crimes and the penalties prescribed to them, This is the law at that time appropriate for the protection directed the government towards e-government and creating a safe environment for this transformation and to address the crimes that may arise as a result of the expansion of electronic trading which falls within the objectives of criminal policy dealing with the policy of criminalization and punishment policy, and the policy of interdiction and prevention. The culmination of the above legislation and decisions of the regulatory authority in the Kingdom issued the "Law of electronic trading," Royal Decree No. (M/ 18) dated 08/03/1428 H, which aims to adjust all procedures for transactions and electronic signatures, organize and provide the legal framework to it, and is this law major shift in the legislative structure of the electronic trading system and to regulate and control transactions and electronic signatures and give them authentic in evidence and specify in detail the binding legal framework for these workers at the official level or a personal level [17].

Than during the above it is clear that the legal environment has become an integrated and comprehensive e-government project in Saudi Arabia as a result of these laws and regulations were opportunities Authentic this shift towards egovernment precedes a number of countries that still lack the laws and regulations necessary for this transformation and then provide safe products check welfare and the economic and social climate and the successful management of the government and the individual.

\section{A COMPARISON OF E- GOVERNMENT IN SAUDI ARABIA WITH OTHER GULF COUNTRIES}

In this section, to study for a brief period in the e-government projects in the three Gulf countries in order to identify good practices and comparing and contrasting the progress with regard to management, strategy and implementation of egovernment services, Table 1. 
Table 1. E-Government Development Index for other gulf country

\begin{tabular}{|l|c|c|c|c|}
\multirow{2}{*}{ Country } & \multicolumn{2}{c|}{ EGDI } & 2010 & 2012 \\
\cline { 2 - 5 } & 2010 & 2012 & 49 & 27 \\
\hline United Arab Emirates & 0.5349 & 0.7344 & 13 & 36 \\
\hline Bahrain & 0.7363 & 0.6946 & 58 & 41 \\
\hline Saudi Arabia & 0.5142 & 0.6658 & 82 & 64 \\
\hline Oman & 0.4576 & 0.5944 & & \\
\hline
\end{tabular}

In the Gulf states, emerged the United Arab Emirates as the new leader of the value of 0,7344 EGDI, and occupies 27 place ranking in the world in the study in 2012. They provide their citizens with a wealth of information and e-services, and links to national websites and the ministry. Saudi Arabia in
2012 and placed in 41 th position in the world worth $\$ 0.6658$, as shown in Figure 1 [12].

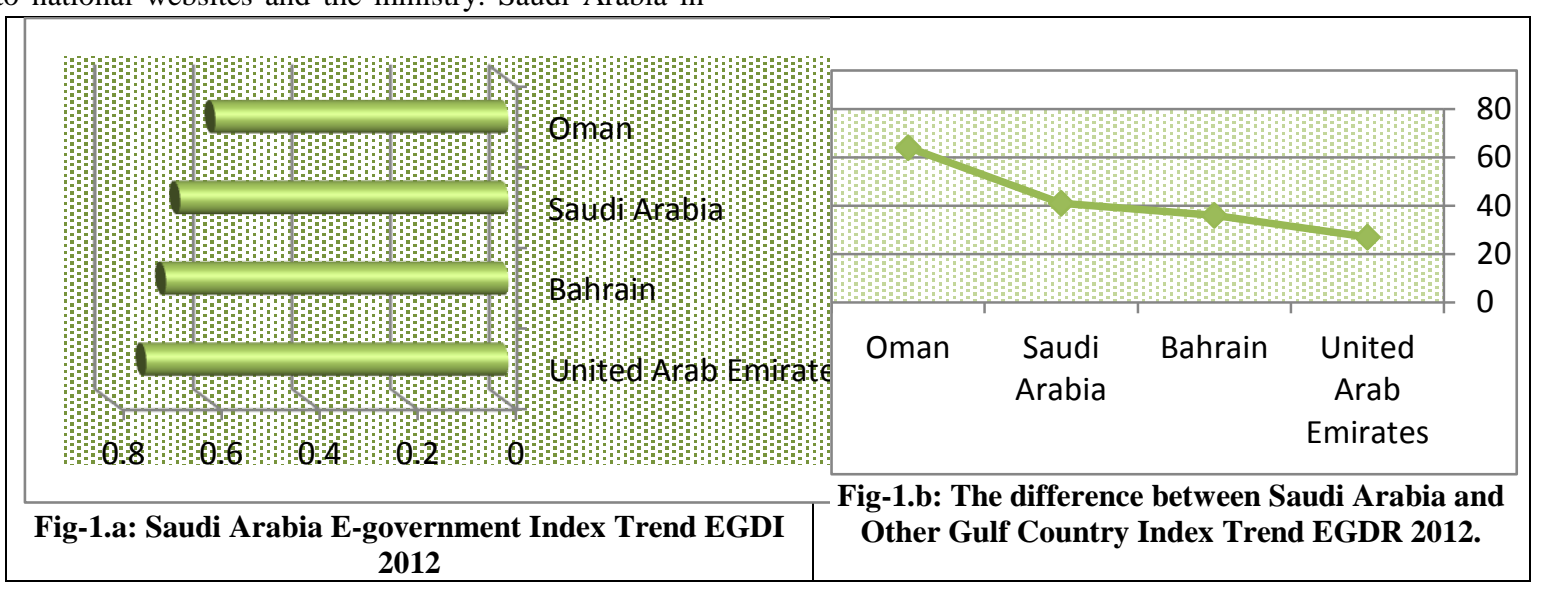

EGDI in 2010 developed a United Nations study of Saudi Arabia's position 58 in e-government world with EGDI of
0.5142. In the Gulf States, Oman lags far behind for 82 , as shown in Figure 2.

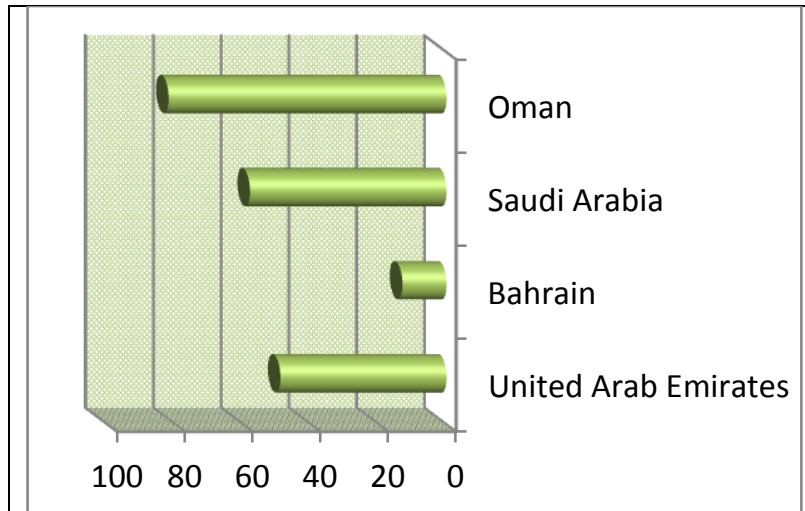

Fig-2.a: Saudi Arabia E-government Index Trend EGDI 2010

\section{CRITICAL CHALLENGES FACING SAUDI E GOVERNMENT}

Challenges faced by governments and local authorities in the development of new methods of management and a wide range depending on the scope of e-government initiatives of this kind. The overall success depends on the ability of egovernment planners to identify challenges or respond to emergencies through the integration of response mechanisms in e-government solutions provided or specify a range of

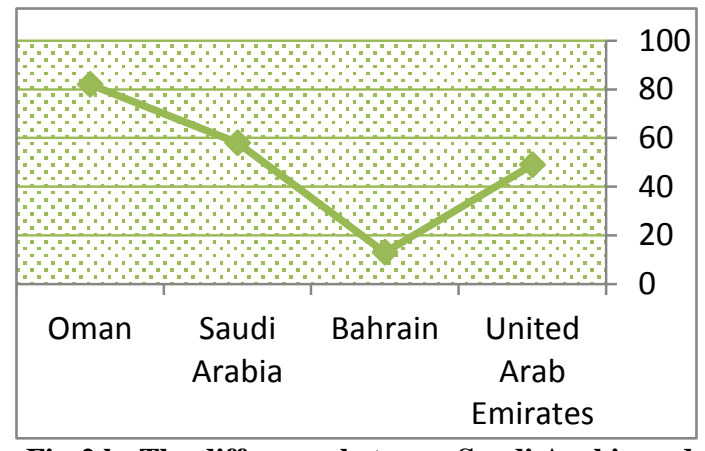

Fig-2.b: The difference between Saudi Arabia and Other Gulf Country Index Trend EGDR 2010.

projects that fall between the cracks of the challenges cannot be overcome. In the following sections, we try to identify the critical challenges of the E-Government of Saudi Arabia to face on the road to safety [8].

\subsection{Government transformation and reform}

E-government requires a coherent strategy, ranging from the nation's political will, resources, and regulatory environment, and the ability of people to take advantage of planning 
technologies. The only thing that can be said about the strategies adopted by the GCC in general with regard to egovernment is that it is the poor and the reaction at best. Most of which is configured on information technology that it plans instead of the comprehensive plans of IT governance and communications. Despite claims to the contrary, there does not seem that there is a serious attempt to formulate a clear vision to repair or change the government through information and communication technology. And motivation to focus only on technical solutions by the bureaucratic culture that are not citizens of the government agents, not involved in the decision-making.

\subsection{E-Citizen participation}

The concept of e-government, ranging from a focus on improving efficiency and progress towards a more customercentric effort, including the shift towards participatory government, which seeks to achieve e-democracy. So far, confirmed most of the e-government projects offered by one of the services on the Internet, instead of interaction in both directions, and re-drafting of the government's role in a new democratic era with its citizens. Citizen participation can cluster into two major categories, political and administrative [9].

\subsection{Citizen access, security and privacy}

While the social and political structure of the government and bureaucracy in aging and possibly seriously stall the development of $\mathrm{G} 2 \mathrm{C}$ services in the fourth stage, the government is not only one to blame, as is generally believed that the be skeptical citizens in the absorption of the government changes. The name was coined suffer from egovernment systems of the soft factors - people, politics, emotions and culture.

\subsection{Managing the e-government program}

One of the major obstacles that have been slow to develop egovernment Saudi Arabia is the lack of a central authority to oversee the implementation of the program. Cabinet voted a resolution on March 27, 2006, to enforce the rules for the implementation of e-government. However, another requirement is for government entities to demonstrate compliance, and thus frustrate the corrective action early if necessary. Despite being in fact part of a five-year information technology plan, there is no entity or a single entity responsible for digital migration of the entire government.

\subsection{Evaluation, accountability and transparency}

Saudi Arabia seems to be one vision lacks a clear strategy and deployment of e-government services. Decrees have done new structures and restructuring to give a little boost to the existence of serious government transactions on the network. The experts pointed out that King's office should be responsible for the e-government project with the individual in charge, after the rank of minister some sort of fantasy governor-mail, and that may be even at the ministerial executive level [10].

\subsection{Cultural and soft barriers}

Where there is no universal model of e-government implementation, it is necessary to take into account the demographic and cultural influences, political, economic, and privacy. This would reduce the gap in fact a design that was found to be the main reason for the failure of e-government projects in all parts of the developing world. However, Saudi
Arabia and similarly for all countries in the region rely heavily on consultants to develop a place of global egovernment projects. This inevitably leads to consider a bit of soft factors in the development of e-government. Could have been behind the idea of Executive Committee, chaired panacea Saudi Computer Society to include e-government Saudi Arabia with aspects of soft desired response but it is a certainty that such a committee cannot impose the vision and mission of the recommendations that could come with the bureaucrats on Saudi Arabia, thinking the grass.

\subsection{Interoperability of e-government platforms}

In the past, it has flooded systems from all leading vendors (IBM, Oracle, Microsoft, Cisco, HP, etc.) in the Kingdom of Saudi Arabia with the concepts already being tested (sometimes in close proximity and similar to Abu Dhabi) [11].

\section{CONCLUSION}

This study found that the implementation of e-government efforts in the Kingdom of Saudi Arabia is still in its early stages and that the country faces a number of challenges in this regard. Among the most prominent factors that have been identified as posing significant challenges for the implementation of e-government is the lack of strategic frameworks, leadership, and legal and regulatory issues related to infrastructure. Requires the Government of the Kingdom of Saudi Arabia to develop a set of policies and regulations to promote access to development sites and promoting the use of information and communication technology to facilitate the needs of citizens in the context of e-government.

On the bright side, though, does not seem to Saudi Arabia for lack of resources or a solution, has been summed up in the phrase, "Nothing in the Kingdom of Saudi Arabia is impossible, but nothing is easy." There are already clear signs of change and we believe that e-government will be dynamic to pay for major breakthroughs. Must be competitive pressures from neighboring countries in the region such as Oman, Bahrain and the United Arab Emirates highlights the real value of the sleeping giant.

\section{REFERENCES}

[1] Abuali, Amer; Alawneh, Ali; Mohammad Hassan. Factors and Rules Effecting in E-Government, European Journal of Scientific Research, ISSN 1450-216X Vol.39 No.2 (2010), pp.169-175.

[2] Al-Azzam, Ahmed Hassan Mohammed (2001) Egovernment in Jordan: the possibilities of the application, unpublished Master Thesis, Jordan, Yarmouk University.

[3] United Nations 2012, E-Government Survey 2012: Leveraging e-government at a time of financial and economic crisis, Department of Economic and Social Affairs, Division for Public Administration and Development Management, New York.

[4] Berntzen, L., \& Olsen, M.G. (2009). Benchmarking egovernment: A Comparative Review of three International benchmarking Studies. In the Proceedings of the 3rd International Conference on Digital Society (pp.77-82).

[5] Maher O. Al-Fakhri. International Journal of Electronic Government Research, Vol. 4, Issue 2, edited by M. Khosrow-Pour, pp. 59-85, copyright 2008 by IGI Publishing (an imprint of IGI Global). 
[6] Al-Nuaim, Hana Abdullah. An Evaluation Framework for Saudi E-Government, Journal of e-Government Studies and Best Practices http://www.ibimapublishing.com/journals/JEGSBP/jegsb p.html Vol. 2011 (2011), Article ID 820912, 12 pages DOI: $10.5171 / 2011.820912$.

[7] Meso, P., Checchi, R., Sevcik, G., Loch, K., \& Straub, D. (2006). Knowledge spheres and the diffusion of national IT policies. The Electronic Journal of Information Systems in Developing Countries, 23.

[8] Sofiane Sahraoui et al. e-Government in Saudi Arabia: Can it overcome its Challenges, Brunel University, West London UB8 3PH, UK, September 112006.

[9] Suh, S. "Promoting Citizen Paticipation in e Government" (From the Korean Experience in eParticipation). Available on the Worlwide web. URL, August 24.2005. http://unpan1.un.org/intradoc/groups/public/documents/u n/unpan020076.pdf)

[10] Rada, J. 2006. Our E-Bureaucracy Is Wrapped in Red Tape" Presentation at the Saudi CIO Summit, Riyadh, 21 February.

(http://www.arabnews.com/?page $=11 \&$ section $=0 \&$ article $=78164 \& \mathrm{~d}=21 \& \mathrm{~m}=2 \& \mathrm{y}=2006$ ) [accessed April 7th 2006].
[11] Madar Research, 2005. e-government in GCC, Chapter VI Saudi Arabia, Madar Research Group, Dubai Media City, UAE, pp. 65-82, June.

[12] United Nations Department of Economic and Social Affairs. "United Nations E-Government Survey 2012". UN.

http://unpan1.un.org/intradoc/groups/public/documents/u n/unpan048065.pdf. Retrieved 2010-04-30.

[13] Alshomrani, Saleh. A Comparative Study on United Nations E-Government Indicators between Saudi Arabia and USA, Journal of Emerging Trends in Computing and Information Sciences, VOL. 3, NO. 3, ISSN 2079-8407, March 2012.

[14] Al-Bayoumi, Abdel Fattah, E-government, Alexandria thought House, 2006.

[15] Al-Sudairi, Muhammad ibn Ahmad, research Mekdn to the Seventh National Congress of the computer, Saudi Abdulaziz University, 2006.

[16] Radwan, Raafat, management and the new global variables, the second administrative Forum for Saudi Management Association, March, 2004.

[17] Panel of Experts Saudi Council of Ministers link: www boe gov sa. 